\title{
DE CIENCIA, TECNOLOGÍA Y DESARROLLO NACIONAL
}

Hoy en día el quehacer nacional se ve afectado profundamente por lo que ocurre en el resto del mundo, incluyendo por cierto el quehacer científico. Ohan Guvenen, Director del Instituto de Investigaciones de los Sistemas Económicos y Estratégicos Mundiales, ha hecho notar que el difuso y continuo acceso a todo lo que el mundo ofrece, es decir la globalización, ya no es una elección sino una realidad con la cual es preciso convivir. Es la característica socioeconómica que identifica nuestro tiempo a partir de la caída del muro de Berlín, el 9 de noviembre de 1989 y el posterior colapso de la Unión Soviética. Se ha señalado que la globalización a priori no es ni buena ni mala sino es lo que las personas hagan de ella. En este contexto, cuando los altos ejecutivos de las transnacionales toman decisiones rara vez se hacen responsables de las consecuencias que tienen para las personas cuyas vidas se ven afectadas por éstas. Resulta fundamental que la educación en estos tiempos debe ir más allá de los programas tradicionales. Debe proporcionar habilidades empresariales, idiomas extranjeros, entrenamiento en prácticas democráticas y fundamentalmente conocimientos científicos y tecnológicos avanzados. Las generaciones futuras deben estar preparadas para enfrentar este nuevo escenario mundial globalizado y para ello es preciso derribar las barreras políticas, económicas y religiosas que aún impiden el libre acceso al saber de los pueblos. La comunidad científica internacional, incluyendo la chilena, no puede ignorar su responsabilidad de contribuir a construir una nueva sociedad, la sociedad del saber, que regule la expansión desmedida de los mercados que hasta el momento sólo ha beneficiado a un porcentaje menor de la población mundial. En este contexto resulta esencial destacar los aspectos más importantes que afectan el adecuado desarrollo del sistema científico chileno.

Una entrevista realizada recientemente por la periodista de la Academia de Ciencias del Instituto de Chile, Paula Zañartu, a numerosos miembros de la Academia y a personalidades del mundo político y empresarial, contiene interesantes opiniones sobre temas relacionados con el quehacer científico nacional. Sin duda esta entrevista puede representar una contribución importante a cualquier discusión sobre ciencia, tecnología y desarrollo y, pensamos, bien podría servir de base para el presente análisis.

En primer lugar cabe destacar el consenso existente entre los entrevistados sobre la importancia de vincular el quehacer científico y tecnológico chileno al desarrollo nacional y de incrementar las vinculaciones entre la comunidad científica y el mundo empresarial. Este aspecto es interesante y contrasta con la posición de muchos científicos que fueron maestros de la generación actual, que rechazaban de plano esta relación y se inclinaban por la llamada "ciencia pura". Esta tenía la característica de no estar contaminada con apetencias económicas de ninguna especie. Era, lo que podría llamarse, una ciencia lúdica.

En línea con los postulados de la globalización, actualmente casi todos coinciden en que se requiere innovación, lo que naturalmente no excluye la posibilidad de seguir realizando ciencia lúdica. Ésta ha demostrado ser insospechadamente importante para el avance científico y cultural de la humanidad. Basta recordar la Grecia de Pericles. Al referirnos a innovación pensamos en la creación de valor económico a través de la transformación de ideas o conocimientos en nuevos bienes o servicios. Las ideas, el conocimiento y la innovación se han constituido en el principal recurso económico (L. Michea, Boletín Académico Universidad de Chile, 2007). Según A. Greenspan “el producto económico de los EEUU se ha transformado en un producto predominantemente conceptual". Algo similar ocurre en Europa y los países asiáticos, especialmente Japón.

Coinciden los entrevistados en que en Chile se hace buena ciencia, sobre todo en comparación con nuestros vecinos, pero que el número de científicos es excesivamente bajo. Esta observación es correcta. Si comparamos, por ejemplo, el número de científicos que trabajan en Chile (1,5 por 1.000 trabajadores) con Nueva Zelanda o Finlandia nos encontramos con diferencias enormes. El número de investigadores en estos países es respectivamente seis y diez veces mayor. La producción científica chilena de cerca de 120 trabajos por millón de habitantes también es diez veces más pequeña que la de Finlandia (OECD Economic Survey of Chile, 2005). Está de más referirse al escuálido número de patentes registradas, por inventores chilenos, en comparación con los países usados como referencia. 
En consecuencia, los entrevistados plantean elevar el número de becas de doctorado y procurar la inserción laboral de los doctores en las universidades y en las empresas a través de reestructuraciones de la planta académica y la creación de incentivos tributarios.

Actualmente $35 \%$ de los postulantes a becas es financiado por la Comisión Nacional de Investigación en Ciencia y Tecnología (CONICYT). El número de becas ha aumentado en cerca de cinco veces entre el año 2000 y 2007 . Esto significa que habrá un mayor número de investigadores que postulen a Proyectos del Fondo Nacional de Desarrollo Científico y Tecnológico (FONDECYT) de Iniciación. De modo que éstos deberán aumentar tanto en número como en duración para permitir que los científicos jóvenes logren durante el desarrollo del proyecto un número suficiente de publicaciones que les permita competir por proyectos regulares que ciertamente también deben aumentar.

Se plantea la necesidad de contar con mayores aportes estables para hacer ciencia y desarrollar tecnología en Chile. El recientemente creado royalty minero se inserta dentro de este tema, pero desafortunadamente su elaboración e implementación no fue suficientemente sociabilizada creando suspicacias. Por otra parte, se ha hecho notar (L. Michea; Boletín Académico Universidad de Chile, 2007) que el documento elaborado por la consultora Boston Consulting Group a petición del Consejo Nacional de Innovación para la Competitividad recomienda productos y servicios chilenos que podrían eventualmente beneficiarse de la innovación, que no corresponden a aquellos con mayor valor agregado. Esto conlleva la necesidad de contar con un programa de desarrollo de la ciencia y tecnología dentro de un marco institucional estructurado con apoyo de la comunidad científica. No han faltado las conversaciones en ese ámbito sobre la posibilidad de plantear a las autoridades la transformación de CONICYT en un Ministerio de Ciencia y Tecnología.

Cabe destacar además, en este contexto, que de los aportes estatales al desarrollo del sistema científico chileno, correspondientes aproximadamente al 0,7\% del PIB (Producto Interno Bruto), solamente un 5\% de éste llega directamente a la comunidad científica nacional. En efecto, la mayoría de estos recursos son asignados sin concursos a varias instituciones gubernamentales con el propósito de realizar investigaciones cuyos resultados en la mayoría de las oportunidades no son publicados y a los cuales los científicos e ingenieros chilenos difícilmente pueden acceder.

Por último, a los aspectos mencionados debemos agregar uno de gran relevancia. Nos referimos a la deficiente formación en ciencias de los profesores de enseñanza básica y media con las consecuentes falencias exhibidas por los alumnos que postulan a las universidades y entre los cuales estarán los futuros científicos innovadores. Este problema fue discutido por una Comisión integrada por miembros del Ministerio de Educación, la Academia de Ciencias y la Asociación de Profesores de Ciencia hace unos años. Esperamos que actualmente esté en vías de ser resuelto.

Resumiendo, entre los problemas generales más relevantes que dificultan la innovación en Chile están sin duda la falta de recursos humanos y de financiamiento estable adecuado y los problemas educacionales, es decir, el llamado “apagón cultural". No obstante, existen otros factores que inciden negativamente en la innovación. Por ejemplo, la dudosa costumbre de sectores gubernamentales de excluir de la toma de decisiones a importantes sectores de la ciudadanía que tienen experiencia en el tema tratado y de priorizar la solución de problemas puntuales contingentes. Inciden también factores como la poca motivación y visión económica cortoplacista de numerosos integrantes del mundo empresarial. En lugar de informarse en forma adecuada sobre los nuevos conocimientos e investigaciones e implementar adecuadamente un programa científico tecnológico chileno, la mayoría de los empresarios privilegia la importación de tecnologías. No cabe duda que el fomento de la innovación en Chile es un tema complejo que requiere de políticas imaginativas y sobre todo de la participación de todos los actores, es decir, científicos, ingenieros, funcionarios de gobierno, empresarios, profesores y estudiantes, entre otros.

Francisco Rothhammer

Instituto de Alta Investigación - Universidad de Tarapacá

Arica, Chile

Facultad de Medicina - Universidad de Chile

Santiago, Chile 